\title{
Creative Movement as an Approach to Learning Science in the Preschool Period
}

\author{
Marjanca Kos, Gordana Schmidt, Janez Jerman \\ University of Ljubljana, Ljubljana, Slovenia
}

\begin{abstract}
Moving and sensory consciousness are the main ways children learn about their world and themselves. Learning is facilitated when a child's entire body is involved (Boyd, Chalk, \& Law, 2003; Chandler \& Tricot, 2015; Davies, 2003; Gallahue, Werner, \& Luedke, 1975; Gilbert, 2004; Joyce, 1994). The outdoor environment is an ideal place for children to play and learn, since it offers an incredible wealth of sensory experiences (Wilson, 2008). In our project, preschool children (aged 4-5) were offered a direct early science experience and the chance to express it through creative movement. We selected a few science topics (spiders, beetles, a toad, a caterpillar, grasses, trees, rotating maple, linden and ash tree fruits, rain and wind) and conceived outdoor activities that included: an experience and the act of experiencing, learning from the experience and re-living the experience through creative movement. We video recorded the activities. When analyzing the recordings, we focused on evaluating the elements of creative movement (the use of different body parts, space, direction, levels, ranges, pathways, speed, force, and rhythm). We focused our attention on the children's genuine and credible movement responses and on stereotypical movements. Before each activity, we asked the children to depict a certain science topic by movement, which was based on their own previous ideas and knowledge about the topic. We used those results in the comparison with the movements after the direct experiences. Our results show that nature and direct contact with living beings motivated children to discover new ways of movement and new kinaesthetic senses, develop body orientation and learn the meaning of movement expressions. Through direct contact with nature and expression through movement we achieved increased focus in the child's on an animal, plant, or natural phenomenon. Children used body language to express their experience, emotions, thoughts, and attitude toward topics dealt with, and thus reinforced the early science knowledge they had gained. The children's movements were original, non-stereotypical, and we noticed significant progress in their use of creative movement elements. Group activities promoted children's social development and positive emotions toward nature. An early science experience changed the child's way of observing nature. So the child, and later the adult, can become more sensitive to nature and more responsible in his/her actions.
\end{abstract}

Keywords: creative movement, early science, outdoor learning, preschool children, experiential learning

\section{Introduction}

Creative movement stimulates cognitive learning. Moving and sensory consciousness are the main ways

Marjanca Kos, Ph.D., Senior Lecturer, Faculty of Education, University of Ljubljana.

Gordana Schmidt, Assistant Professor, Faculty of Education, University of Ljubljana.

Janez Jerman, Ph.D., Associate Professor, Faculty of Education, University of Ljubljana. 
children learn about their world and themselves. Learning is facilitated when a child's entire body is involved (Boyd et al., 2003). Intellectual, physical and emotional growth is stimulated through movement experiences (Chandler \& Tricot, 2015; Davies, 2003; Gallahue et al., 1975; Gilbert, 2004; Joyce, 1994). Experiences in movement exploration allow the children to express themselves in non-verbal terms. This can be very important for the inarticulate child (Gilbert, 2002).

Young children are fascinated by the natural world. They know and experience the natural world differently to adults (White, 2008; Wilson, 2008). According to Rachel Carson (1956), the child knows the world as being "fresh and new and beautiful, full of wonder and excitement". As for adults, Carson says: "It is our misfortune that for most of us that clear-eyed vision that true instinct for what is beautiful and awe-inspiring, is dimmed and even lost before we reach adulthood".

The natural environment is an ideal place for children to engage in creative play. It offers an incredible wealth of sensory experiences and open-ended materials (materials that can be used in a wide variety of ways) for motoric manipulation. Experiences in natural outdoor playspaces promote the holistic development of children as they foster growth in all of the developmental domains, including adaptive, cognitive, aesthetic, communication, sensorimotor and socioemotional. Another advantage of play in a natural environment is the lessening of aggressive behaviours (Wilson, 1995). The quality of play also tends to be richer in natural environments, where children engage in more creative forms of play (including fantasy and pretend play) than in playgrounds or "prepared" indoor playspaces (Wilson, 2008).

Creative play in natural environments also fosters the development of an environmental ethics, which must start at the early childhood level, as this is the period of life when basic attitudes and values are established (Wilson, 1994). The most effective way to instill a lifelong sense of caring and responsibility for the natural world is to give young children frequent positive experiences with the world of nature. Unless children have frequent positive interactions with the natural world, they are likely to develop unfounded fears and prejudices about nature that impede the development of an environmental ethic (Wilson, 2008).

Knowledgeable and enthusiastic adults are crucial to unlocking the potential of outdoors (White, 2008).

Preschoolers learn about nature primarily through experience and creative play (Wilson, 2008). Their experience of nature and natural phenomena facilitates spontaneous learning that ultimately leads to permanent, useful knowledge and an accomplished attitude toward all living beings. The kindergarten teacher's single most important role during this period is to facilitate children's early science experiences, and to use his knowledge to "feed" the children's curiosity arising out of such experiences. At the preschool level, the interdisciplinary approach to curricular areas is a prerequisite, and there are no limitations to the way the teacher intertwines different topics. Children can re-live their early science experiences in various ways, thus verbally, by drawing or painting, through music or through creative movement.

\section{Methods}

Our project combined science and creative movement. We conducted a single-group experiment having one treatment. The activities were conducted with a group of 15 preschool children aged 4-5. There were 6 boys and 9 girls.

We selected a few science topics and conceived activities that included:

(1) an experience and the act of experiencing;

(2) learning from the experience; and 
(3) re-living experience through creative movement.

We video recorded the activities. When analyzing the recordings, we focused our attention on the children's genuine and credible movement responses and on stereotypical movements.

We evaluated the elements of creative movement (the use of different body parts, body movement, steps, level, direction, range, space, pathways, rhythm and force) using a 3 -score scale (Table 1).

Table 1

A 3-Score Scale for Evaluation of the Elements of Creative Movement

\begin{tabular}{|c|c|c|}
\hline Element of creative movement & Value & Score \\
\hline & only legs or only arms & 1 \\
\hline \multirow[t]{3}{*}{ Body parts } & almost entire body & 2 \\
\hline & entire body & 3 \\
\hline & one kind & 1 \\
\hline \multirow[t]{3}{*}{ Body movement } & two kind & 2 \\
\hline & more kinds & 3 \\
\hline & one kind & 1 \\
\hline \multirow[t]{3}{*}{ Steps } & two kinds & 2 \\
\hline & three kinds & 3 \\
\hline & one & 1 \\
\hline \multirow[t]{3}{*}{ Level } & two & 2 \\
\hline & more & 3 \\
\hline & one & 1 \\
\hline \multirow[t]{3}{*}{ Direction } & two & 2 \\
\hline & more & 3 \\
\hline & one & 1 \\
\hline \multirow[t]{3}{*}{ Range } & two & 2 \\
\hline & more & 3 \\
\hline & one & 1 \\
\hline \multirow[t]{3}{*}{ Space } & two & 2 \\
\hline & more & 3 \\
\hline & one kind & 1 \\
\hline \multirow[t]{3}{*}{ Pathway } & two kinds & 2 \\
\hline & more kinds & 3 \\
\hline & one & 1 \\
\hline \multirow[t]{3}{*}{ Rhythm } & two & 2 \\
\hline & more & 3 \\
\hline & one kind & 1 \\
\hline \multirow[t]{2}{*}{ Force } & two kinds & 2 \\
\hline & three kinds & 3 \\
\hline
\end{tabular}

Before each activity, we asked the children to depict a certain science topic by movement, which was based on their own previous ideas and knowledge about the topic. We used those results in the comparison with the movements after the direct experiences.

Using the statistical analysis software IBM SPSS Statistics, we computed means and standard deviations for numbers of elements of creative movement before and after the activities.

We examined the differences in the numbers of elements of creative movement by applying the related one-tailed $t$-test and effect size. We also examined the differences in means for the boys and girls by applying 
the two-tailed $t$-test for independent data and effect size (Coolican, 2014).

\section{Animals}

Children in the kindergarten tend to mimic animals (fly like birds, hop like rabbits, lumber like bears, etc). The majority of these movements are stereotypical and have little resemblance to the actual animals' movements. Children often make artificial moves, blindly mimicking their peers or teacher. Up to the age of three, stereotypes are acceptable. However, many children hold on to stereotypical movement even in later stages of development.

Our activities focused on the children's immediate experience with live animals.

The children got to know and experienced: a caterpillar, a toad, a slow worm, spiders and bugs.

The children even bred some animals in their playroom, so that they were in contact with them for a longer period and got to know them better.

We created situations in which the animal moved, and encouraged the children to watch it closely. We observed how the animal: walked, ran, hopped, crawled, swam, how it moved when it ate, how it moved when it was frightened, etc.

We paid special attention to children who showed fear or any other negative emotion when in contact with an animal. With a great deal of sensitivity we applied the so-called model for the elimination of prejudice toward animals and remedied this.

Immediately after their experience with an animal, all children were motivated to re-live their new knowledge through movement. If their moves were stereotypical, we encouraged them to recall the experience. If they felt the need to get in touch with the animal again, the children could do so at this stage too.

\section{Plants}

Many preschoolers think plants do not move at all. For this reason, they often satisfy themselves that plants are not alive (Zozga \& Papamichael, 2000). It is true that plant movements are far less conspicuous then the movements of animals, but we can nevertheless create conditions to help children sense them and re-live them through their own motion.

The children can experience both active plant movements (for example by watching beans sprout) as well as passive plant movements (the rotating of maple, linden and ash tree fruits or movements of grass).

\section{Example activities}

\section{Toad}

The kindergarten teacher found a toad in the kindergarten playground. It was an excellent object to include in the project.

The children got to know the toad. They opened their palms and if they wanted to hold it, we placed the animal into their hands. They had sufficient time for their first contact with the animal. At this initial stage, we used almost no verbal communication, since the powerful emotion of the children's experience made it redundant.

Gradually the children began asking questions about the toad. They were motivated to learn something new.

They wanted to know how far it can leap. We put the animal on the ground and it went on a slow crawl. As it moved, it stretched its hind legs, leaving them far behind. 
When stroking it, the children realized the toad's skin is soft and warty.

They looked at its nostrils, noticing the constant lifting and lowering of its mouth floor.

We showed them how its eye contracts into the skull if we touch it. When the eye reappeared, the children noticed the nictitating membrane - the clear inner eyelid that covers their eyes when underwater. The children called it "the toad's swimming glasses".

Some children were curious about what the toad ate. To answer them, we produced an insect larva. When the toad sensed it, it turned its gaze toward it. Its body turned rigid, its head protruding far ahead of its front legs and its moves jerky. Its tongue extruded in one rapid move and brought the larva back into its mouth. Immediately afterwards its eyeballs went down into its head and it devoured the larva. The children wanted to see this again, so we placed the larva into their open palms and had the toad eat from their hands. For an instant, they could sense the feel of its soft, moist tongue on their palms.

We then put the animal into a puddle. The toad took to swimming and the children saw that with each stroke the animal stretched its hind legs in the same way they do when they swim froggy style.

Even as they were still experiencing the animal, some children began to spontaneously re-live the experience. We encouraged others to follow suit.

The children used all parts of their bodies to imitate the toad, moved inside the lower and mid levels, changing the speed of their movements, muscle tension, gaze direction — and thus put on display for us to watch a myriad of creative movement elements.

We set up an aqua-terrarium in the playroom and had the children take care of the toad. The fear that some children had felt upon their first contact with the animal had disappeared.

\section{Rotating Maple and Lime Tree Fruits}

The children were taken outside to observe and play with the fruits of the maple and lime trees.

The fruits of these trees have wings on them, making them act like little helicopters.

The children played with the seeds, making observations about how they twirled about their axes and spun in various directions.

They collected the fruits and took them back to the kindergarten, where they continued to experiment with them.

They tried dropping them from various heights and various quantities.

The children also extended their observations into physical movement. They pretended to be fruits, twirling around in various combinations, changing speed, directions and levels.

The children also planted some seeds. They observed germination process and made the connection between fruits and trees. Also this experience was re-lived through movement.

\section{Results}

\section{Toad}

The mean numbers for all elements of creative movement after the activities are higher than the mean numbers before the activities. These increases are highly statistically significant $(p<0.050)$. The mean differences (effect sizes) are very large, too $\left(\eta^{2}>0.140\right)$.

The differences between means for boys and girls are not significant $(p>0.050)$, effect sizes are very small $\left(\eta^{2}<0.010\right)$. 


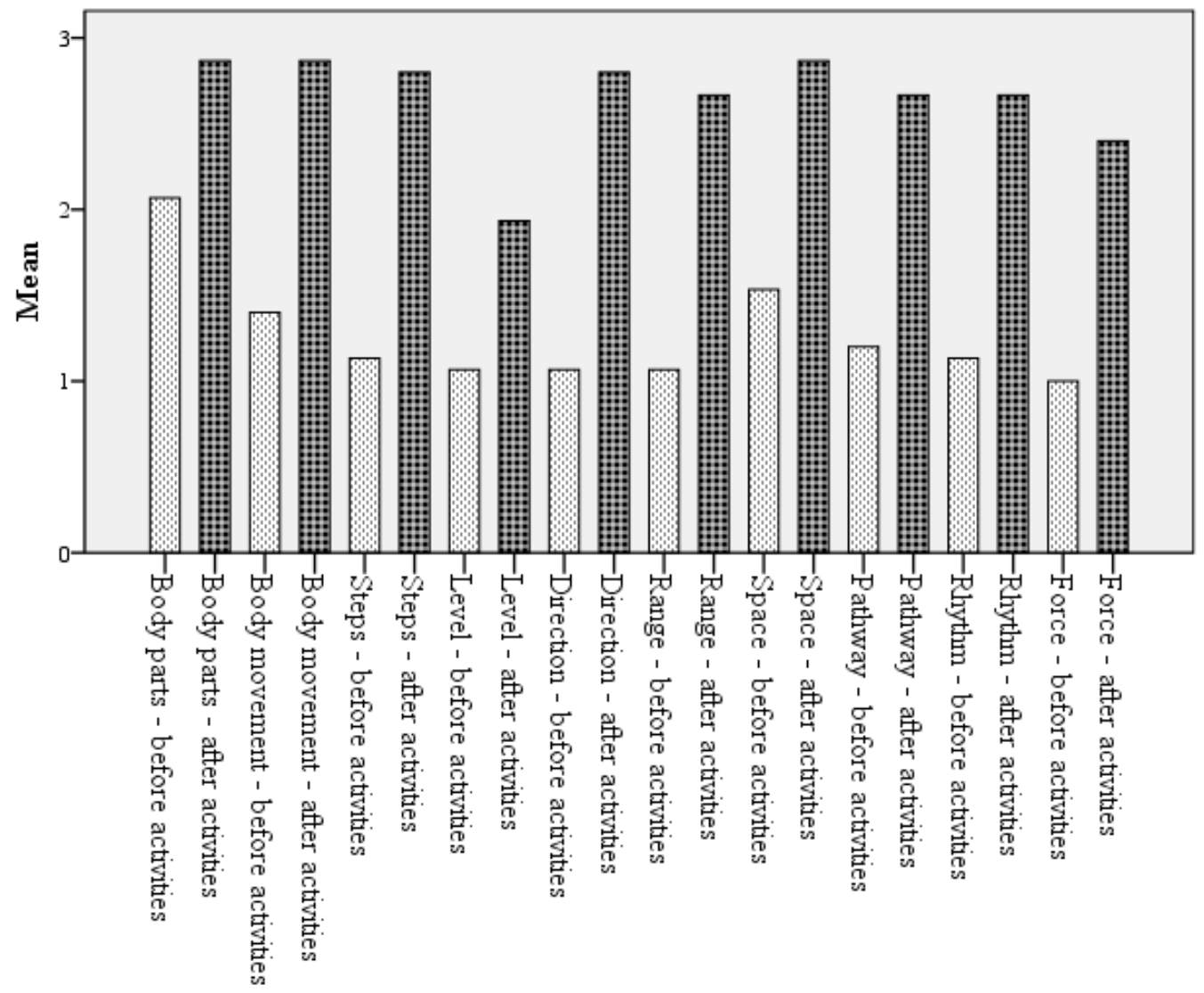

Figure 1. Means for elements of creative movement before and after activities—a toad.

Table 2

T-test and Effect Size for Elements of Creative Movement-A Toad

\begin{tabular}{lllll}
\hline $\begin{array}{l}\text { The element of } \\
\text { creative movement }\end{array}$ & $t$ & $d f$ & $\begin{array}{l}p \\
\text { (one-tailed) }\end{array}$ & $\begin{array}{l}\text { Effect size } \\
\eta^{2}\end{array}$ \\
\hline Body parts & -5.527 & 14 & 0.000 & 0.686 \\
Body movement & -11.000 & 14 & 0.000 & 0.896 \\
Steps & -13.229 & 14 & 0.000 & 0.926 \\
Level & -9.539 & 14 & 0.000 & 0.867 \\
Direction & -14.666 & 14 & 0.000 & 0.939 \\
Range & -12.220 & 14 & 0.000 & 0.914 \\
Space & -8.367 & 14 & 0.000 & 0.833 \\
Pathway & -11.000 & 14 & 0.000 & 0.896 \\
Rhythm & -11.500 & 14 & 0.000 & 0.904 \\
Force & -10.693 & 14 & 0.000 & 0.891 \\
\hline
\end{tabular}

\section{Grass}

Also here we can see statistically significant improvement in the use of most of creative movement elements.

The mean numbers for body parts, body movement, level, direction, range, rhythm, and force as elements of creative movement after activities are higher than the mean numbers before activities. These increases are highly statistically significant $(p<0.050)$. The mean differences (effect sizes) are very large, too $\left(\eta^{2}>0.140\right)$. 


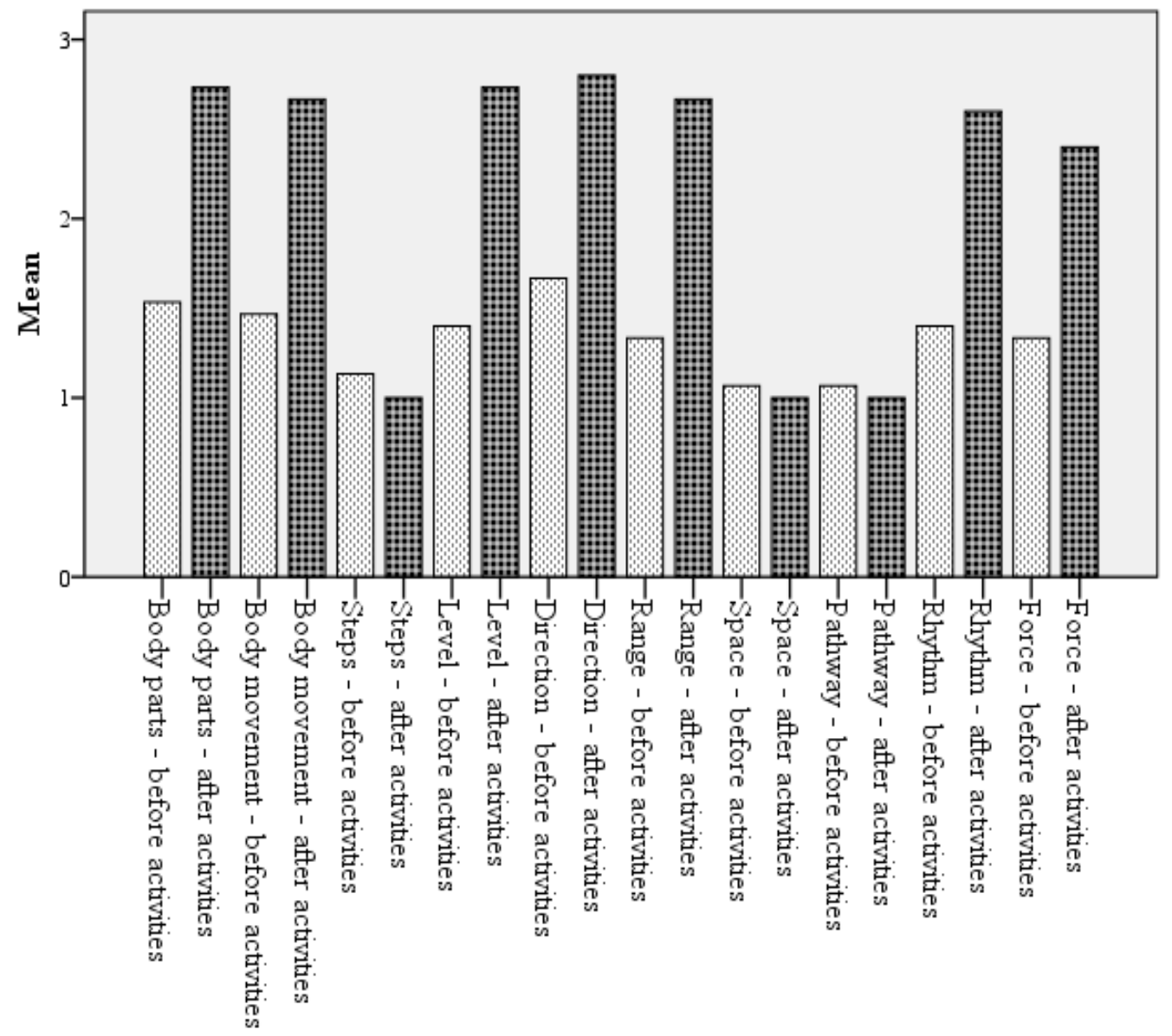

Figure 2. Means for elements of creative movement before and after activities—grass.

Table 3

T-test and Effect Size for Elements of Creative Movement-Grasses

\begin{tabular}{lllll}
\hline $\begin{array}{l}\text { The element of creative } \\
\text { movement }\end{array}$ & \multicolumn{1}{l}{$\begin{array}{l}p \\
\text { (one-tailed) }\end{array}$} & $\begin{array}{l}\text { Effect size } \\
\eta^{2}\end{array}$ \\
\hline Body parts & -6.874 & 14 & 0.000 & 0.771 \\
Body movement & -8.290 & 14 & 0.000 & 0.831 \\
Steps & 1.468 & 14 & 0.082 & 0.133 \\
Level & -8.367 & 14 & 0.000 & 0.833 \\
Direction & -5.906 & 14 & 0.000 & 0.714 \\
Range & -10.583 & 14 & 0.000 & 0.889 \\
Space & 1.000 & 14 & 0.167 & 0.067 \\
Pathway & 1.000 & 14 & 0.167 & 0.067 \\
Rhythm & -6.000 & 14 & 0.000 & 0.720 \\
Force & -5.172 & 14 & 0.000 & 0.656 \\
\hline
\end{tabular}

The mean numbers for steps, space, and pathway as elements of creative movement after activities are lower than the mean numbers before activities. The differences between means are not significant $(p>0.050)$, and the mean differences (effect sizes) are small to moderate $\left(\eta^{2}>0.060\right)$.

The differences between means for boys and girls are not significant $(p>0.050)$, and the mean differences (effect sizes) are very small $\left(\eta^{2}<0.010\right)$. 


\section{Conclusions}

Nature and direct contact with all living beings motivated children to discover new ways of movement and new kinaesthetic senses, develop body orientation and learn the meaning of movement expressions.

Children used body language to express their experience, emotions, thoughts, and attitude toward topics dealt with, and thus reinforced the early science knowledge they had gained.

The children's movements were original, non-stereotypical, and we noticed significant progress in their use of creative movement elements.

The experience made them realize how each of them placed special emphasis on certain specifics, and this only encouraged them to keep an even closer watch. Looking at each other move, they borrowed each other's motifs and so the object of observation evolved into new and richer content. They learned from nature and from their peers. They commented on each other's moves and supplemented each other.

The activities promoted children's social development and positive emotions toward nature.

The natural outdoor places offered new discoveries and a lot of space to express through creative movement.

We conclude that an early science experience changes the child's way of observing nature. The child, and later the adult, becomes more sensitive to his surroundings and more responsible in his actions. And this is precisely what we would like to achieve.

\section{References}

Boyd, K. S., Chalk, M. S., \& Law, J. S. (2003). Kids on the move: Creative movement for children of all ages. Flower Mound: Creative Publishing.

Carson, R. (1956). The sense of wonder. New York: Harper \& Row.

Chandler, P., \& Tricot, A. (2015). Mind your body: The essential role of body movements in children's learning. Educational Psychology Review, 27, 365-370.

Coolican, H. (2014). Research methods and statistics in psychology (6th ed.). New York: Psychology Press.

Davies, M. (2003). Movement and dance in early childhood. London: Paul Chapman Publishing.

Gallahue, D. L., Werner, P. H., \& Luedke, G. C. (1975). A conceptual approach to moving and learning. New York: John Wiley $\&$ Sons.

Gilbert, A. G. (2002). Teaching the three Rs through movement experiences: A handbook for teachers. Bethesda: National Dance Education Organization.

Gilbert, A. G. (2004). Creative dance for all ages. Reston: American Alliance for Health, Physical Education, Recreation and Dance.

Joyce, M. (1994). First steps in teaching creative dance to children. Mountain View: Mayfield Publishing Company.

Ocepek, R. (2005). Model pouka za odpravo predsodkov do živali (Model for the elimination of prejudice toward animals). Zbornik drugega strokovnega posveta: Didaktika $v$ šoli v naravi (Proceedings of Second conference: Didactics in outdoor school) (pp. 76-83). Ljubljana: CŠOD.

Wallace, R. A., Sanders, G. P., \& Ferl, R. J. (1996). Biology: The science of life (pp. 662-663). New York: HarperCollins Publishers.

White, J. (2008). Playing and learning outdoors: Making provision for high-quality experiences in the outdoor environment. Abingdon: Routledge.

Wilson, R. (1994). Environmental education at the early childhood level. Day Care and Early Education, 22(2), 23-25.

Wilson, R. (1995). Nature and young children: A natural connection. Young Children, 50(6), 4-11.

Wilson, R. (2008). Nature and young children: Encouraging creative play and learning in natural environments. New York: Routledge.

Zozga, V., \& Papamichael, Y. (2000). The development of the concept of alive by preschoolers through a cognitive conflict teaching intervention. European Journal of Psychology of Education, 15(2), 191-205. 